\title{
The practical management of bleedings during treatment with direct oral anticoagulants: the emergency reversal therapy
}

\author{
Luca Masotti, ${ }^{1}$ Giancarlo Landini, ${ }^{2}$ Grazia Panigada ${ }^{3}$ \\ ${ }^{1}$ UO Medicina Interna, Ospedale di Cecina (LI); ${ }^{2}$ UO Medicina Interna, Ospedale Santa Maria Nuova, Firenze; ${ }^{3}$ UO Medicina \\ Interna, Ospedale di Pescia (PT), Italy
}

\begin{abstract}
Bleeding represents the most feared complication of the new oral anticoagulants, direct oral anticoagulants (DOACs), as well as all the antithrombotic therapies. During the acute phase of bleeding in patients taking anticoagulants, restoration of an effective hemostasis represents the cornerstone of practical management. While vitamin K antagonists are effectively and promptly reversed by specific antidotes such as prothrombin complex concentrates (PCCs), fresh frozen plasma or vitamin $\mathrm{K}$, it is still not clear how to manage the urgent reversal of DOACs during life-threatening or major bleedings due to the lack of specific antidotes. However, in vitro and ex vivo studies have suggested some potential strategies to reverse DOACs in clinical practice, other than general support measures that are always recommended. Activated charcoal could be used in subjects with DOAC-related bleedings presenting to the emergency department within two hours of the last oral intake. Non-activated or activated PCCs (FEIBA) and recombinant activated Factor VII (raFVII) seem to be the optimal strategy for urgent reversal of dabigatran, while non-activated PCCs seem to have efficacy in reversing rivaroxaban. Due to its low plasma protein binding, dabigatran could be also dialyzed in urgent cases. Clinically relevant non-major bleedings and minor bleedings should be treated with general and local measures, respectively, and, when necessary, with dose delay or drug withdrawal. In this article, the Authors describe the practical approach to bleedings occurring during DOACs treatment.
\end{abstract}

\section{Introduction}

Phase III randomized clinical trials (RCT) have demonstrated non-inferiority in terms of efficacy and safety of new oral anticoagulant molecules, the direct oral anticoagulant (DOACs) inhibitors of thrombin (dabigatran) or activated Factor X (rivaroxaban, apixaban and edoxaban) in the prevention of venous thromboembolism (VTE) in the setting of major orthopedic surgery, VTE treatment in the acute, long-term and ex-

Correspondence: Luca Masotti, UO Medicina Interna, Ospedale di Cecina, via Montanara, loc. Ladronaia, 57023 Cecina (LI), Italy.

Tel.: +39.0586.614212 - Fax: +39.0586 .614218 .

E-mail: luca.masotti@tin.it

Key words: new oral anticoagulants, dabigatran, rivaroxaban, apixaban, warfarin, prothrombin complex concentrates, bleedings, reversal, antidote.

Received for publication: 24 April 2013.

Revision received: 4 July 2013.

Accepted for publication: 8 June 2013.

This work is licensed under a Creative Commons Attribution NonCommercial 3.0 License (CC BY-NC 3.0).

(C) Copyright L. Masotti et al., 2013

Licensee PAGEPress, Italy

Italian Journal of Medicine 2013; 7(s8):48-58

doi:10.4081/itjm.2013.s8.48 tended phases, and in cardioembolic prevention of nonvalvular atrial fibrillation (NVAF) ${ }^{1-4}$ Furthermore, on many safety end points, DOACs have been shown to be significantly superior to comparators in reducing relative risk of bleeding and, of utmost importance, all DOACs have been associated with a significant reduction in intracranial bleeding risk, especially when compared to warfarin in NVAF, this trend being confirmed from post-marketing reports..$^{5-7}$ DOACs have also favorable pharmacokinetic and pharmacodynamic characteristics, such as brief half-life and fast elimination after withdrawal which are extremely important when bleeding occurs. ${ }^{8}$ Despite these positive aspects, the incidence of DOAC-related bleedings is not negligible and their optimal management is, therefore, of the utmost importance in clinical practice.

\section{Definition of severity of antithrombotic-related bleeding}

The correct identification and estimation of their severity is essential for the optimal management of antithrombotic-related bleedings. Many definitions for antithrombotic-related bleedings have been proposed over the years, especially useful for the safety end points in RCTs on antithrombotic drugs but applicable also in routine clinical practice. The International Society on Thrombosis and Haemostasis (ISTH) identifies major 
and minor bleedings. Major bleeding events include fatal bleedings and bleedings occurring in critical sites such as central nervous system, eyes, pericardium and thorax, gastrointestinal lumen, peritoneum and retroperitoneum, joints and those proving compartmentalization syndrome or a fall in hemoglobin levels of at least $2 \mathrm{~g} / \mathrm{dL}$ or the need for at least 2 red cell packs or requiring invasive or surgical maneuvers to stop bleeding. All bleeding events that do not fit the abovementioned criteria are considered minor. ${ }^{9}$ Phase III RCT on DOACs have used similar bleeding definitions but with special considerations. Adjunctive definitions of lifethreatening major bleedings and clinically relevant nonmajor bleedings have been used to distinguish these events from major and minor bleedings. Table 1 shows definitions for bleedings used in phase III RCTs on DOACs in NVAF. ${ }^{10-13}$

Therefore, site and entity represent the cornerstone for the correct approach of antithrombotic-related bleedings on which appropriate management strategies should be performed. ${ }^{9}$ Life-threatening and/or major bleedings are clinical emergencies needing prompt specific and general measures, respectively, aimed at neutralizing the antithrombotic effect of drugs (urgent reversal) and restoring adequate and effective hemostasis, and offer medical or surgical support treatment for management of the consequences of blood loss, such as acute anemia with tissue hypoxia or mass effect in critical sites such as the brain in intracranial bleedings. ${ }^{9}, 14$

\section{Urgent reversal of vitamin $K$ antagonists and other antithrombotic drugs}

The concept of urgent reversal of antithrombotic drugs has been developed specifically for vitamin $\mathrm{K}$ antagonist (VKA)-related major bleedings and it has also been applied for the other antithrombotic drugs. ${ }^{15}$

The only discontinuation of VKAs, besides the need to do so in the context of major bleeding events, proves VKA neutralization in around 3-5 days; therefore, specific measures for their faster neutralization are necessary. ${ }^{16}$ VKAs represent the prototype of drugs with specific antidotes for their reversal, represented by non-activated prothrombin complex concentrates (PCCs), fresh frozen plasma (FFP), recombinant activated Factor VII (raFVII) and vitamin K1. ${ }^{14}$

Despite the fact that the first literature reports on the urgent reversal of VKAs by using non-activated PCCs date back to the $1970 \mathrm{~s},{ }^{17}$ widespread use of PCCs in this context has only developed over the last ten years (Figure 1), even if they are still dramatically underused. ${ }^{18}$ PCCs represent products derived from plasma and containing 3 or 4 non-activated vitamin $\mathrm{K}$ dependent coagulation factors (Factors II, VII, IX and $\mathrm{X}$ ) and distributed in bottles of a few tenths of milliliters. ${ }^{19}$ Three- and 4-factors PCCs differ for the presence of non-activated Factor VII, contained in only 4-factors PCCs. ${ }^{19}$ Intravenous administration of PPCs with the goal of bringing international normalized ratio (INR) to values of 1.5 or under can be assured in

Table 1. Classification of bleedings in phase III randomized clinical trials on DOACs in non-valvular atrial fibrillation.

\begin{tabular}{|c|c|c|c|}
\hline & $\begin{array}{l}\text { RE-LY } \\
\text { (Dabigatran) }\end{array}$ & $\begin{array}{l}\text { ROCKET-AF } \\
\text { (Rivaroxaban) }\end{array}$ & $\begin{array}{l}\text { ARISTOTLE } \\
\text { (Apixaban) }\end{array}$ \\
\hline $\begin{array}{l}\text { Major } \\
\text { bleedings }\end{array}$ & $\begin{array}{l}\text { Hemoglobin fall of at least } 2 \mathrm{~g} / \mathrm{L} \text { or bleeding } \\
\text { requiring at least } 2 \text { packs of red cells } \\
\text { or symptomatic bleeding in a critical site } \\
\text { Sub-group of major bleedings: } \\
\text { - Life-threatening bleedings } \\
\text { - Fatal } \\
\text { - Symptomatic intracranial bleeding } \\
\text { - Hemoglobin fall of at least } 5 \mathrm{~g} / \mathrm{L} \\
\text { - Bleeding requiring at least } 4 \text { packs of red } \\
\text { cells or vasoactive drugs or surgical } \\
\text { approach }\end{array}$ & $\begin{array}{l}\text { Fatal or hemoglobin fall of at least } 2 \mathrm{~g} / \mathrm{L} \\
\text { or bleeding requiring at least } 2 \text { packs } \\
\text { of red cells or symptomatic } \\
\text { bleeding in a critical site: } \\
\text { - Intracranial and central nervous system } \\
\text { - Eye } \\
\text { - Thorax } \\
\text { - Pericardium } \\
\text { - Peritoneum and retro-peritoneum } \\
\text { - Joints } \\
\text { - Gastrointestinal tract } \\
\text { - Compartimentalization syndrome }\end{array}$ & $\begin{array}{l}\text { Fatal or hemoglobin fall of at least } 2 \mathrm{~g} / \mathrm{L} \\
\text { or bleeding requiring at least } 2 \text { packs } \\
\text { of red cells or symptomatic bleeding } \\
\text { in a critical site } \\
\text { - Intracranial and central nervous system } \\
\text { - Eye } \\
\text { - Thorax } \\
\text { - Pericardium } \\
\text { - Peritoneum and retro-peritoneum } \\
\text { - Joints } \\
\text { - Gastro-intestinal tract } \\
\text { - Compartimentalization syndrome }\end{array}$ \\
\hline $\begin{array}{l}\text { Clinically } \\
\text { relevant } \\
\text { non major } \\
\text { bleedings }\end{array}$ & Not contemplated & $\begin{array}{l}\text { Evident bleedings not classified as } \\
\text { major but requiring medical evaluation, } \\
\text { temporary discontinuation or delay } \\
\text { in next dose, proving pain or limiting } \\
\text { activities of daily living }\end{array}$ & $\begin{array}{l}\text { Bleeding requiring hospitalization, } \\
\text { medical or surgical treatment, changing } \\
\text { of antithrombotic treatment }\end{array}$ \\
\hline $\begin{array}{l}\text { Minor } \\
\text { bleedings }\end{array}$ & $\begin{array}{l}\text { All others not entering in major } \\
\text { bleedings definition }\end{array}$ & $\begin{array}{l}\text { All others not entering in major } \\
\text { bleedings or clinically relevant } \\
\text { non-major bleedings }\end{array}$ & $\begin{array}{l}\text { All others not entering in major } \\
\text { bleedings or clinically relevant } \\
\text { non-major bleedings }\end{array}$ \\
\hline
\end{tabular}


a few minutes, allowing prompt VKA reversal. ${ }^{20}$ PCCs are now considered the first choice treatment for urgent reversal of VKA by the main scientific societies. ${ }^{16,21-26}$ When compared with FFP, PCCs guarantee faster VKA reversal and lower volume load. ${ }^{27}$ Volume overload (optimal dose of FFP to reverse VKAs being $15-30 \mathrm{~mL} / \mathrm{kg}$ ), especially worrying in elderly patients or those affected by heart disease, delays due to thawing and $\mathrm{ABO}$ blood group typing, risk of infection and TRALI (transfusion acute lung injury), represent a major limitation in the use of FFP which require at least 4-6 h for VKA reversal. ${ }^{27}$ Factor Eight Inhibitor By-passing Activity (FEIBAs) are PCCs containing Factor VII in activated form and Factors II, IX and X primarly in non activated form and are mainly used in hemophilic patients who develop inhibitors against Factors VIII or IX. ${ }^{28}$ FEIBAs have been used for urgent reversal of VKAs with positive results in terms of efficacy when compared with FFP, but they have still not been recommended for urgent reversal of VKAs and are burdened by high secondary thromboembolic risk. ${ }^{28}$ There is much evidence in the literature to demonstrate that FVIIra is effective for prompt VKA reversal but, unfortunately, it is associated with high risk of arterial and venous thromboembolic complications. Therefore, in contrast to recent experiences, it is not recommended for VKA reversal and its use in this context remains off-label. ${ }^{29,30}$

Intravenous administration of vitamin K1 represents the most used strategy for VKA reversal and is the only strategy to be recognized with recommenda- tion grade IA, but it cannot represent the only strategy for urgent VKA reversal because of its slow onset of action which starts after $2 \mathrm{~h}$ and is only completed after 12-16 h. ${ }^{31}$ However, vitamin K1 should always be administered together with PCCs or FFP because it proves the synthesis de novo of vitamin $\mathrm{K}$ dependent coagulation factors from the liver, permitting stable reversal. PCCs, FFP and raFVII have a brief half-life, therefore, the missed dose of vitamin $\mathrm{K} 1$ could result in a rebound of INR values once the abovementioned measures are no longer in action. ${ }^{32}$ Oral administration of vitamin $\mathrm{K} 1$ represents the treatment of choice for VKA reversal in the context of non-major bleedings or in supra-therapeutic INR due to VKA overdose. ${ }^{33}$

Bringing INR values down to 1.5 or under by urgent reversal helps restore adequate hemostasis and reduces the risk of hematoma enlargement and/or blood loss, significantly increased when INR is in therapeutic range or at supra-therapeutic values. ${ }^{14}$ The model of VKA-related intracranial bleeding is of particular interest in this context in order to understand the positive effect of urgent reversal. ${ }^{34,35}$ Patients on VKAs who develop intracranial bleeding and who do not receive prompt reversal (Figure 2) have more than 3 times the risk of hematoma enlargement compared to non-VKA patients. ${ }^{36}$ Hematoma enlargement occurring in the first hours after symptom onset is associated with more frequent severe neurological deterioration, higher mortality or severe residual neurological disability. ${ }^{37}$ Experimental animal models and clinical studies demonstrate that urgent reversal of

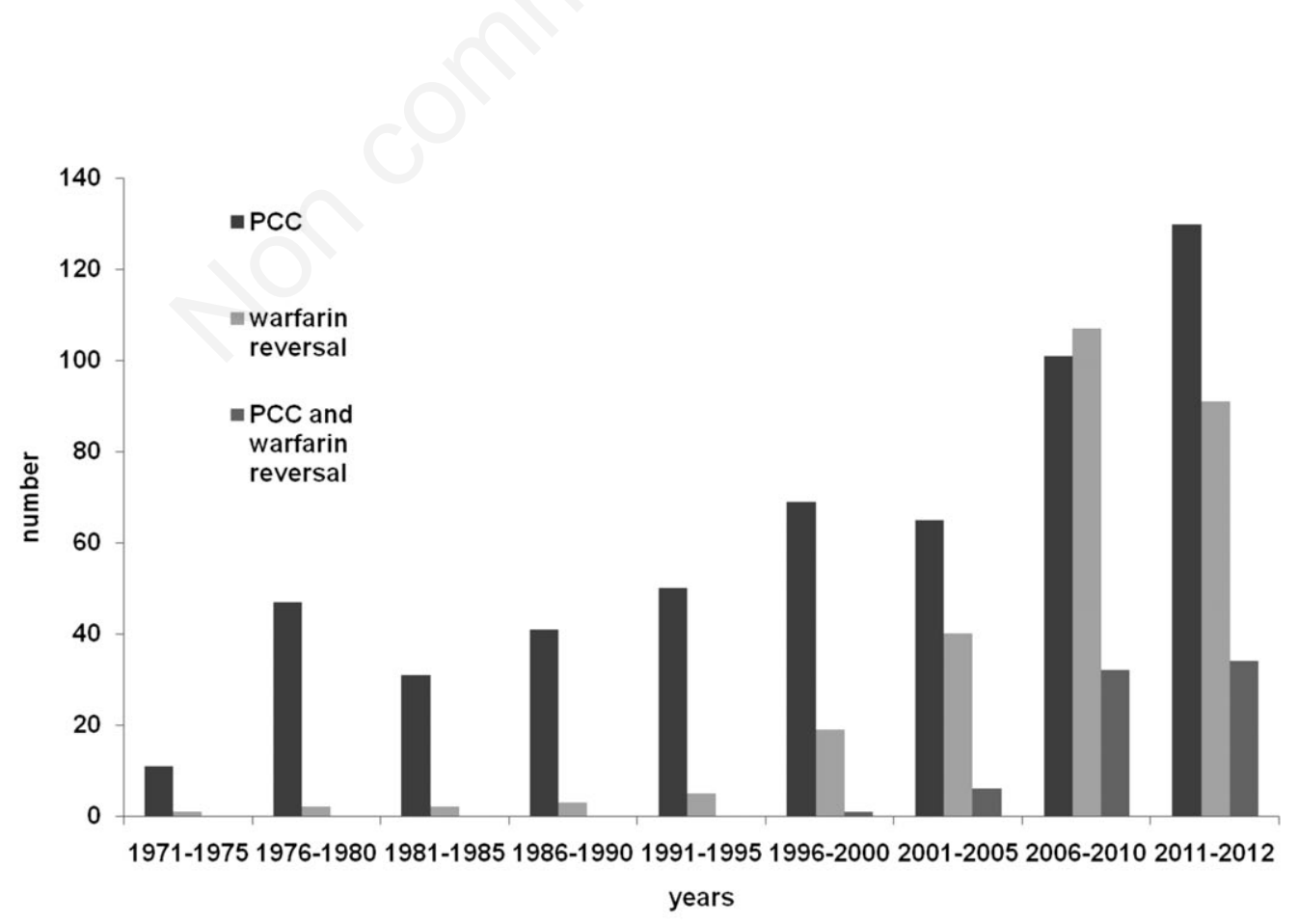

Figure 1. PubMed citations referred to prothrombin complex concentrates for warfarin reversal. PCC, prothrombin complex concentrates. 
VKAs by the use of PCCs reduces hematoma enlargement and a very recent study demonstrates that urgent reversal could be associated with a decrease in mortality. ${ }^{35,38}$ There are concerns about the role of DOACs on hematoma enlargement in intracranial bleedings. Mice and murine models of induced intracranial bleeding demonstrate that pre-treatment with dabigatran and rivaroxaban is associated to hematoma enlargement only when administered at doses aimed to reach supra-therapeutic concentrations, whereas when administered at doses corresponding to therapeutic concentrations hematoma enlargement is not significantly different compared to placebo. ${ }^{39}$ One could speculate that, translating this to human, hematoma enlargement should happen only in patients with DOACs overdose; however, this has not yet been demonstrated in real practice.

Among the other antithrombotic drugs used in clinical practice or studied in clinical trials as anticoagulants, such as recombinant tissue plasminogen activator (rtPA), unfractionated heparin, low molecular weight heparin, fondaparinux, idraparinux or idrabiotaparinux, only protamine sulfate for unfractionated heparin and avidin for idrabiotaparinux (not marketed and not available for clinical practice) are recognized as specific antidotes. ${ }^{40,41}$ In fact, there are some concerns about which is the optimal strategy to apply in rtPA-related bleedings, on the role of protamine sulfate as antidote for low molecular weight heparins on which it seems to have only a partial effect, and raFVII for fondaparinux on which the only evidence in the literature has been in re- ports on experimental animal models or voluntary healthy subjects but outside the context of major bleeding. ${ }^{42,43}$ Furthermore, attention should also be given to the absence of specific antidotes for old and new antiplatelets. ${ }^{40}$ In spite of the fact that platelet transfusion or intravenous administration of desmopressin have been proposed as potential non-specific strategies for antiplatelet-related bleedings, there are no reports in the literature to demonstrate their beneficial effect, especially for intracranial bleedings (Table 2). ${ }^{40,44}$

\section{Strategies for urgent DOACs reversal: evidence in the literature}

The indications for urgent reversal of DOACs are the same as for VKAs and other anticoagulants. The main indications for prompt DOACs reversal include: life-threatening or major bleedings, clinical conditions at high risk of bleeding such as major head injury in patients treated with DOACs, overdose associated with coagulation or platelet disorders or in patients also taking other antithrombotic drugs at the same time, or the need for emergency or urgent surgery. ${ }^{45,46}$

To date, one of the main limitations about the use of DOACS is represented by the absence of specific antidotes for their urgent reversal. ${ }^{8}$

Different strategies aimed at the urgent reversal of the anticoagulant effect of DOACs have been tested, mainly evaluating their effect on normalization of coagulation parameters both in in vitro and in ex vivo ex-
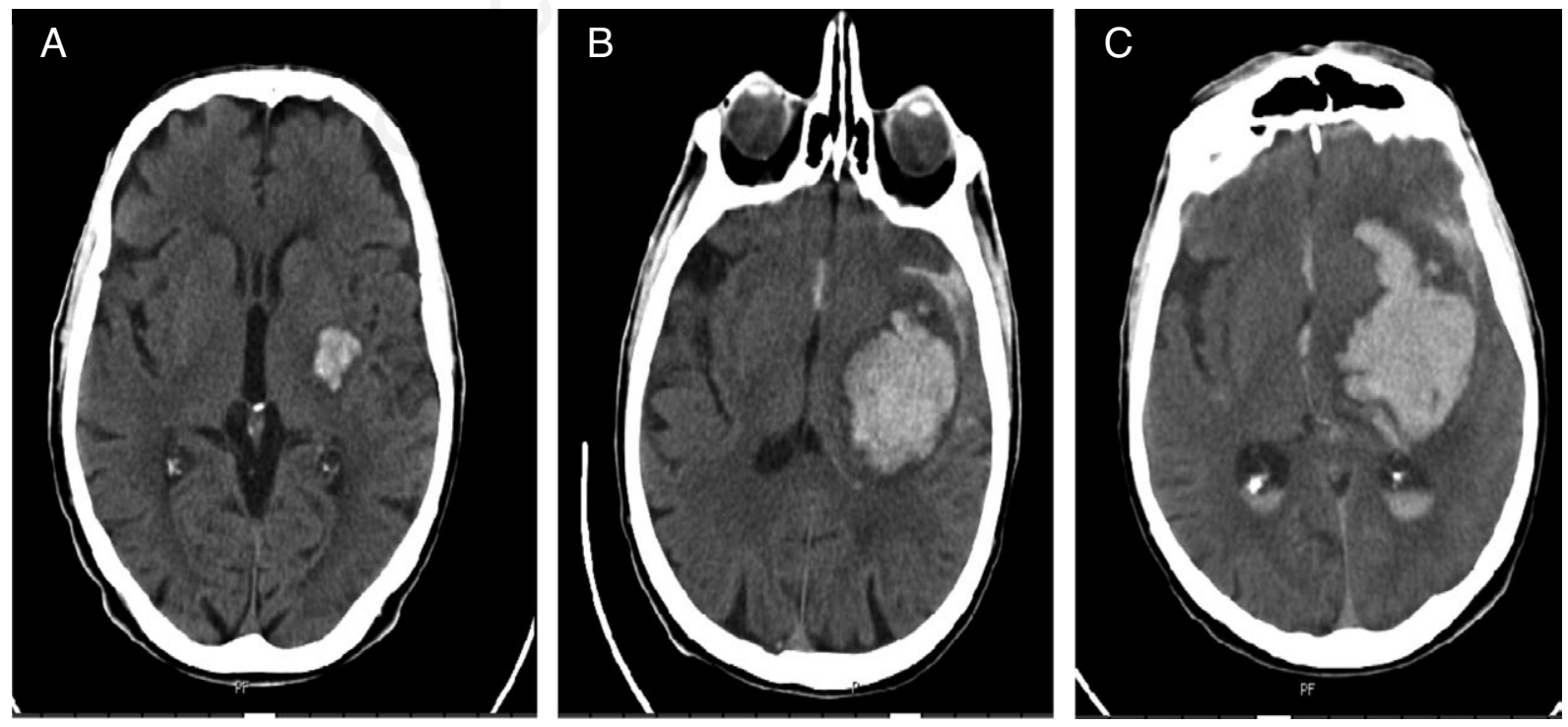

Figure 2. Hematoma enlargement in a delayed reversal of a warfarin-related intracranial hemorrhage. A) Hospital admission: international normalized ratio (INR) 3.1., Glasgow coma scale (GCS): 15/15, treatment: i.v. vitamin K; B) Three hours after admission: GCS 4/15, started treatment with prothrombin complex concentrates INR 1.1 after infusion; C) Eighteen hours after admission: GCS 3/15, INR 0.7. 72 hours after hospital admission death occurred. 
perimental animal models or voluntary healthy subjects taking DOACs. Furthermore, case reports of management of DOAC-related bleedings are also available in the literature. However, there are as yet no solid clinical studies of a numerically relevant size able to extrapolate evidence-based recommendations for clinical practice.

Two in vitro studies have demonstrated that approximately $100 \%$ of the dose of dabigatran can be adsorbed by oral activated charcoal or activated charcoal during hemoperfusion, respectively. ${ }^{47,48}$

In a rabbit model, Pragst et al. demonstrated that a high dose of a 4-factors PCC normalized the blood loss in dabigatran-related induced bleedings. In another animal model pre-treated with dabigatran, the use of PCC was associated with increased thrombin generation but failed to demonstrate the aPTT normalization. ${ }^{49}$

An in vivo mouse model of induced intracranial bleeding demonstrated that PCCs, FFP but not raVII, administered to mice treated with a high dose of dabigatran could reduce the hematoma enlargement. ${ }^{50}$

One in vitro study was conducted on blood of rats pre-treated with edoxaban, an antiXa DOACs still not marketed in Europe, demonstrating that pro-hemostatic non-specific agents, such as 4-factors non-activated PCCs, activated PCCs (FEIBA) and raFVII normalize coagulation parameters. ${ }^{51}$

In a baboon model, a very high dose of raFVII $(210 \mathrm{microg} / \mathrm{kg}$ ) only demonstrated a modest effect on the bleeding time after the intravenous administration of rivaroxaban. ${ }^{48,52}$

Marlu et al. performed an ex vivo study on 10 healthy volunteers randomized to receive dabigatran or rivaroxaban. ${ }^{53}$ After two weeks their blood was taken and subjected to non-specific pro-hemostatic agents. The study showed that dabigatran could be reversed by FEIBA and raFVII but not 4-factors PCC, while rivaroxaban could be reversed by 4 -factors PCC and FEIBA but not raFVII. ${ }^{53}$

Similar results were reproduced by using FEIBA in another ex vivo study on blood samples of 8 healthy volunteers taking dabigatran, demonstrating that these non-specific pro-hemostatic agents increase thrombin generation in a dose-dependent manner and, therefore, indirectly demonstrating the neutralization of dabigatran. ${ }^{54}$

One study performed on 6 volunteers with endstage renal disease demonstrated that dabigatran can be removed by using hemodialysis. ${ }^{55}$

One study enrolling 12 voluntary healthy subjects represents the main literature evidence on in vivo urgent DOACs reversal. ${ }^{56}$ Six subjects receiving dabigatran and 6 receiving rivaroxaban underwent a very high dose of 4-factors PCC (50 UI/ $/ \mathrm{kg}$ ) and their coagulation parameters were measured after infusion. ${ }^{56}$ This study seems to demonstrate that 4-factors PCC is effective for urgent reversal of rivaroxaban but that it is ineffective for dabigatran. It should be underlined that this is a very

Table 2. Summary of reversal strategies for the main antithrombotic drugs used in clinical practice.

\begin{tabular}{|c|c|c|c|}
\hline Drug & Site of action & Specific antidotes & Possible strategies \\
\hline $\mathrm{rtPA}$ & Plasminogen & No & $\begin{array}{l}\text { Tranexamic acid, FFP, fibrinogen } \\
\text { concentrate or cryoprecipitate }\end{array}$ \\
\hline 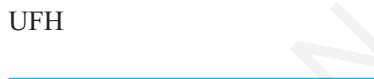 & $\begin{array}{c}\text { Factors Xa and IIa } \\
\text { (ratio 1:1) }\end{array}$ & Protamine suplhate & Protamine suplhate \\
\hline LMWH & $\begin{array}{c}\text { Factors Xa and IIa } \\
\text { (ratio antiXa/antiIIa 4:1) }\end{array}$ & No & $\begin{array}{c}\text { Protamine sulphate at higher dose } \\
\text { compared to UFH }\end{array}$ \\
\hline Fondaparinux & Factor Xa & No & raFVII \\
\hline $\begin{array}{l}\text { Idraparinux } \\
\text { (not available in clinical practice }\end{array}$ & Factor Xa & No & raFVII \\
\hline $\begin{array}{l}\text { Idrabiotaparinux } \\
\text { (not available in clinical practice }\end{array}$ & Factor Xa & Avidin & Avidin \\
\hline VKAs & Factors II, VII, IX, X & $\begin{array}{c}\text { Three or 4-factors PCCs } \\
\text { FFP } \\
\text { Vitamine K1 }\end{array}$ & $\begin{array}{c}\text { Three or 4-factors PCCs } \\
\text { FFP } \\
\text { Vitamin K1 }\end{array}$ \\
\hline $\begin{array}{l}\text { Antiplatelets } \\
\text { ASA } \\
\text { ticlopidine, } \\
\text { clopidogrel, } \\
\text { prasugrel, } \\
\text { ticagrelor }\end{array}$ & $\begin{array}{l}\text { o-oxygenase (COX) inhibition } \\
\text { ADP P2Y12 inhibition }\end{array}$ & No & $\begin{array}{l}\text { Platelets transfusion? } \\
\text { Desmopressin? }\end{array}$ \\
\hline
\end{tabular}

rtPA, recombinant tissue plasminogen activator; FFP, fresh frozen plasma; UFH, unfractioned heparin; LMWH, low molecular weight heparin; VKAs, vitamin K antagonists; PCCs, prothrombin complex concentrates; ASA, acetyl-salycilic acid. 
high dose of PCC corresponding to that required for VKA reversal when INR is 4.0 or over. ${ }^{14}$

There are an increasing number of reports in the literature on clinical cases referring to patients treated with DOACs and developing major bleeding complications. This literature evidence almost solely concerns dabigatran, since this was the first DOACs to be marketed. It is worthy of note that many of these episodes occur in cases of patients on DOACs that do not correspond to drug recommendations, e.g. taking dabigatran in the presence of severe renal failure, a condition in which this drug is absolutely contraindicated. Harper $e t$ al. reported 44 bleeding cases occurring in elderly patients on dabigatran, 12 of them major bleeding events. ${ }^{57}$ The authors found that $25 \%$ of bleedings could be attributed to prescription errors. It is extremely important to consider that 6 patients $(13.6 \%)$ had severe renal failure and $15(34 \%)$ had moderate renal failure, conditions in which dabigatran is absolutely contraindicated or has to be reduced, respectively. ${ }^{57}$ Moreover, the authors found that $50 \%$ of patients weighed less than $60 \mathrm{~kg}$ and the majority of them had not received dose adjustment. Furthermore, $36 \%$ of patients in this case series received blood products, but the authors did not provide any details on these, therefore, it is not possible to extrapolate data on reversal strategy. ${ }^{57}$

Harinstein et al. reported a literature review on the treatment of 13 patients on dabigatran who developed bleeding events. All patients had creatinine clearance below $40 \mathrm{~mL} / \mathrm{min}$. Surprisingly, 5 patients received vitamin $\mathrm{K}$ for urgent dabigatran reversal, 8 FFP, 3 PCCs, and 3 raFVII. Mortality in this case series was $38.4 \%{ }^{58}$

Of great interest, the recent demonstration that 15 patients receiving dabigatran and presenting to the emergency department for bleeding ( 9 major bleedings, 4 life-threatening bleedings), 12 of them gastrointestinal bleedings, received only general support plus red cell transfusion with the exception of 2 patients; one of these with hemo-pericardium, receiving FFP. ${ }^{59}$ Overall mortality was $13 \%$ (100\% in patients treated with FFP $v s$ $0 \%$ in patients not treated with FFP). This case series seems to confirm that FFP is ineffective, and highlights that, in many patients, general support and close monitoring associated with drug withdrawal could be a possible strategy (Table 3). ${ }^{59}$

\section{Future perspectives}

The goal of clinical and pharmacological research on DOACs is represented by the identification of specific antidotes. Extremely important reports aimed at reducing this gap in knowledge have been published very recently. A monoclonal antibody fragment (aDabiFab, antibody-dabigatran-fragment antigen binding) has been studied in vitro and in vivo in a rat model of anticoagulation, demonstrating its property to quickly reverse the anticoagulant effect of dabigatran, while a recombinant protein, representing a truncated form of inactive coagulation Factor Xa, has been studied as universal specific antidotes for oral direct Xa inhibitors ( $\mathrm{r}$ antidote-PRT064445) as well as for LMWH or fondaparinux when bound with antithrombin. In rabbit models, the anticoagulant effect of rivaroxaban was reversed by this recombinant antidote, whereas in rat models the antithrombin-dependent anticoagulation of enoxaparin and fondaparinux was reversed..$^{60,61}$ Despite the fact that these agents still need to be tested in human, this evidence opens the door for the next step of using specific antidotes in DOACs reversal.

\section{Current practical management of DOAC-related bleedings}

Knowledge of pharmacokinetic and pharmacodynamic properties of DOACs is of the utmost importance in order to establish adequate bleeding management strategies in cases related to their use. The brief half-time, in fact, on the one hand allows us to obtain a prompt anticoagulant effect but could otherwise result in a fast elimination after withdrawal in patients with normal renal function. ${ }^{8}$ Therefore, in

Table 3. Summary of recommended strategies for DOACs urgent reversal.

\begin{tabular}{lcc}
\hline & Dabigatran & Anti-Xa \\
\hline Actived charcoal (within two hours from DOACs oral intake) & Yes & Yes \\
\hline Hemodyalisis & Yes & No \\
\hline FFP & No & No \\
\hline raFVII & Possible & Possible \\
\hline PCCs & Yes & Yes \\
\hline FEIBA & Possible & No
\end{tabular}

DOACs, direct oral anticoagulants; FFP, fresh frozen plasma; raFVII, activated recombinant FVII; PCCs, prothrombin complex concentrates; FEIBA, Factor VIII inhibitor by-passing activity. 
clinically relevant non-major bleedings or minor bleedings, apart from general measures for controlling blood loss, the suggested treatments are represented by drug withdrawal which proves elimination in 12$24 \mathrm{~h}$ in the presence of normal renal function, or delaying the next dose, especially if overdose is suspected or confirmed by coagulation assays. ${ }^{62-67} \mathrm{In}$ non-major bleeding, however, the balance between thrombotic and bleeding risk should be taken into account when withdrawal of the drug is a possible option. In patients with high thrombotic risk, discontinuation of antithrombotic drugs could, in fact, represent an extremely hazardous choice, despite being justified by bleeding.

In patients with renal failure, more time is required for DOACs elimination. However, this is generally less ( $<3$ days) than that needed for VKA elimination after their withdrawal (3-5 days). ${ }^{8}$ Maintaining adequate diuresis with fluids support is, therefore, imperative in DOCA-related bleedings. ${ }^{62-67}$

When major DOAC-related bleedings occur within $2 \mathrm{~h}$ of the last drug oral intake, activated charcoal could be a potential choice because it blocks the gastrointestinal drug adsorption. ${ }^{62}$ Despite the fact that this has only been tested for dabigatran, this seems to be a reasonable option for all DOACs. ${ }^{62}$

The relatively low plasma protein binding (35\%) permits the use of hemodialysis for accelerating plasma clearance of dabigatran and this characteristic could be used in the occurrence of major bleedings or in other conditions needing urgent drug reversal. ${ }^{62}$ However, especially in the occurrence of intracranial bleeding, urgent hemodialysis could be an option that is not easily available in hospitals serving a catchment area with a population of $150,000-300,000$ people (first-level hospitals).

Once adsorbed, the pharmacokinetics of DOACs has a valley-peak profile. ${ }^{68-70}$ Mean time to reach plasmatic peak concentration is approximately $2-3 \mathrm{~h}$, with some differences seen between the single DOACs. ${ }^{8,68-}$ ${ }^{70}$ After reaching peak concentration, plasmatic concentration of DOACs progressively falls over the following hours with the lowest level being reached before the next dose administration (valley) ${ }^{8,68-70}$ This concept is made clear by the analysis of coagulation parameters influenced by DOACs and is well described in dose-finding studies. ${ }^{71-73}$ At the moment of peak concentration of dabigatran, diluted thrombin time (dTT), ecarin clotting time (ECT) and aPTT are increased 2-3 fold compared to basal values, whereas before next dose administration they are increased by 1.5 -fold. ${ }^{74}$ Similar considerations are possible for rivaroxaban by measuring prothrombin time (PT) with rivaroxaban-sensitive thromboplastins, anti-Xa activity or aPTT ${ }^{75}$ It should be noted that both for dabigatran and for antiXa molecules, relief of coagulation parameters increased by 2-fold before the next dose administration is associated to higher risk of bleedings. ${ }^{74,75}$ On the other hand, within $2 \mathrm{~h}$ of oral intake, coagulation parameters could be normal or near normal and anticoagulant activity of DOACs could be missed or underestimated in this phase. ${ }^{74,75}$ Therefore, it is of the utmost importance to know the timing of the last dose intake.

This short background is of utmost importance in clinical practice, especially in the context of urgent reversal. Despite the definition of solid evidence-based guidelines, consensus on practical management of DOAC-related bleedings recommends urgent reversal when there is clear evidence of a DOACs anticoagulant effect. In other words, when there is evidence of prolonged coagulation parameters while all appropriate coagulation parameters monitored are in the normal range, urgent reversal seems not to be indicated, at least in cases in which the anticoagulant activity is detected after $2 \mathrm{~h}$ from the last oral intake. ${ }^{62-67}$ Since there is a wide variability in the anticoagulant effect of DOACs on coagulation parameters according to the different reagents used, it is imperative to know which assay method is adopted in each laboratory. Unfortunately, many laboratory methods suggested for DOACs monitoring are not available in many laboratories, especially those of first levels hospitals, such as dTT, ECT, or antiXa activity. ${ }^{76,77}$ Due to its wide availability, the ISTH has very recently proposed the use of aPTT as the screening method to be used to determine the relative grade of dabigatran anticoagulation and to be used in the emergency setting, and dTT as the method for assessing the dabigatran concentration. ${ }^{78}$ A normal dTT demonstrates very low or undetectable dabigatran concentration and anticoagulant activity. ${ }^{78}$ In the same way, PT performed by using a specific thromboplastin for rivaroxaban should be used in the emergency setting to detect the relative grade of anticoagulation, whereas the antiXa activity should be used to detect the rivaroxaban concentration levels. ${ }^{78}$ It is unclear whether this approach could be proposed for apixaban.

Based on the abovementioned available literature, 4-factors PCCs (25-50 UI/kg) or raFVII (90-120 microg $/ \mathrm{kg}$ ) or FEIBA (30-50 FEIBA Units/kg) and/or hemodialysis with active charcoal represent possible choices for urgent reversal of dabigatran, while 4-factors PCCs are currently considered the first choice for urgent reversal of rivaroxaban and edoxaban, but these strategies need to be verified and confirmed in the context of bleeding patients. ${ }^{62-67} \mathrm{It}$ is unclear whether urgent reversal of apixaban may be performed as well as the other antiXa, due to the lack of experimental studies and evidence in the literature. A very recent report of Diaz MQ et al. in the context of gastro-intestinal major bleedings in five patients taking dabigatran 


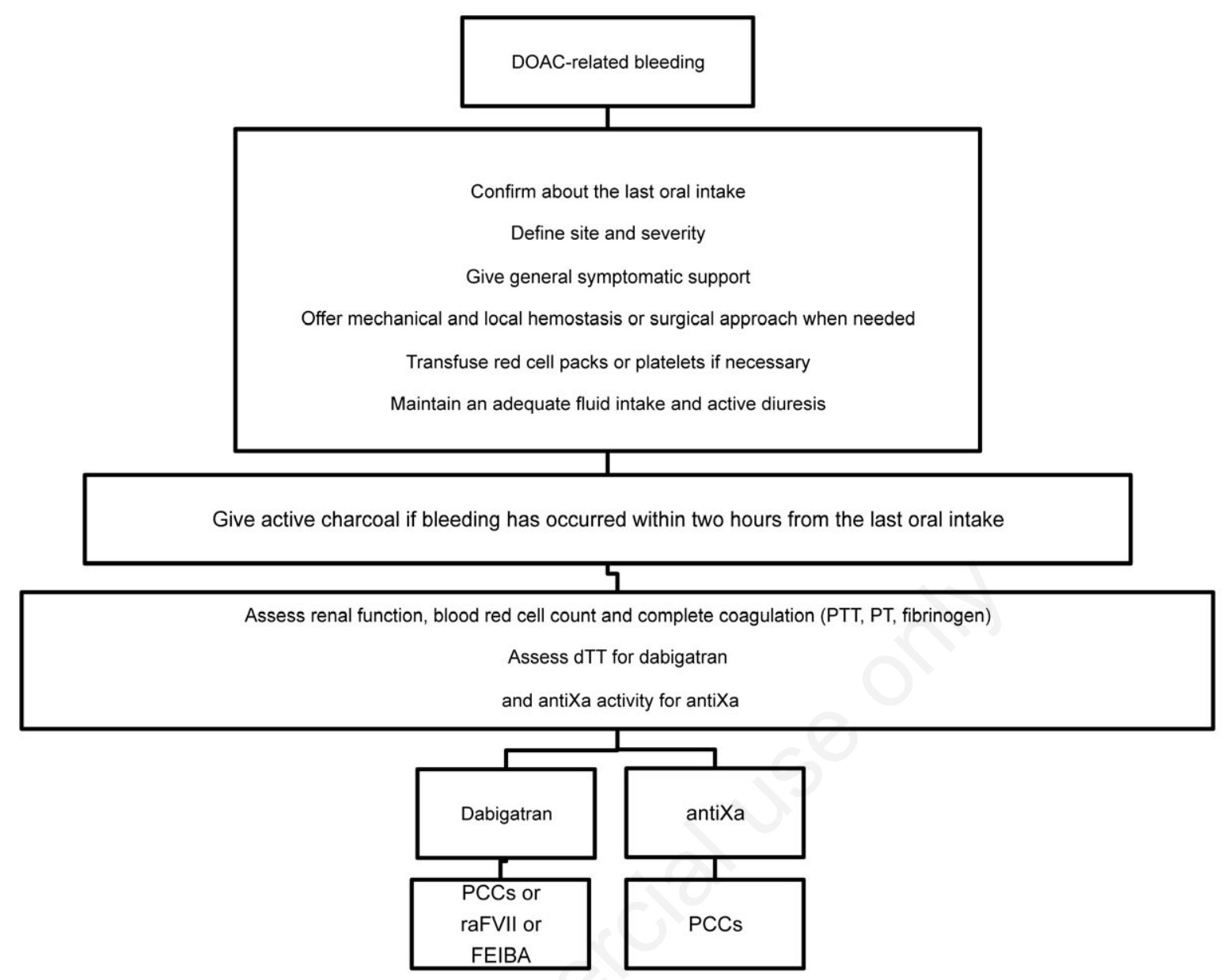

Figure 3. Flow chart for the practical management of DOAC-related major bleedings.

shows that 4-factors PCC seem to be effective in stop bleeding. ${ }^{79}$

After urgent reversal, also of VKAs, monitoring of coagulation parameters should be performed but, again, it is still not clear if an adjunctive dose should be administered in the case of permanence of prolonged coagulation parameters as for VKAs when the INR remains over 1.5 after the first dose of PCCs..$^{14} \mathrm{In}$ the abovementioned study of Diaz MQ et al. the aPTT was not significantly modified from 4-factors PCC, despite the fact that bleeding was stopped by its use. ${ }^{79}$ Therefore clinical judgment more than coagulation parameter should drive the choice of administering an adjunctive dose of 4-factors PCC for avoiding too high doses of 4-factors PCCs and pro-thrombotic risks. Practical recommendations suggest repeating 4-factors PCC no more than 2-fold. ${ }^{80}$

Figure 3 reports a possible management flow chart suggested for DOAC-related bleeding based on bleeding severity.

\section{Conclusions}

Phase III RCTs and post-marketing surveys have shown the efficacy and safety of DOACs, at least when compared to the comparator anticoagulants. However, the bleeding risk remains and is unavoidable due to their anticoagulant properties. Despite the current lack of specific antidotes, strategies demonstrating effectiveness at least in in vitro or ex vivo studies, or in clinical practice in countries where DOACs are already marketed, should be adopted. In any case, studies aimed at validating the best strategies for clinical practice are urgently required.

\section{References}

1. Gómez-Outes A, Terleira-Fernández AI, Suárez-Gea ML, Vargas-Castrillón E. Dabigatran, rivaroxaban, or apixaban versus enoxaparin for thromboprophylaxis 
after total hip or knee replacement: systematic review, meta-analysis, and indirect treatment comparisons. BMJ 2012;344:e3675.

2. Goldhaber SZ, Bounameaux H. Pulmonary embolism and deep vein thrombosis. Lancet 2012;379:1835-46.

3. Dentali F, Riva N, Crowther M, et al. Efficacy and safety of the novel oral anticoagulants in atrial fibrillation: a systematic review and meta-analysis of the literature. Circulation 2012;126: 2381-91.

4. Becattini C, Vedovati MC, Agnelli G. Old and new oral anticoagulants for venous thromboembolism and atrial fibrillation: a review of the literature. Thromb Res 2012; 129:392-400.

5. Kwong JS, Lam YY, Yan BP, Yu CM. Bleeding of new oral anticoagulants for stroke prevention in atrial fibrillation: a meta-analysis of randomized controlled trials. Cardiovasc Drugs Ther 2013 Feb;27:23-35.

6. Masotti L, Di Napoli M, Godoy D, et al. Efficacy and safety of new oral anticoagulants compared with warfarin in cardioembolic prophylaxis of patients with non valvular atrial fibrillation. More lights than shadows. Ital J Med 2012;6:153-69.

7. Southworth MR, Reichman ME, Unger EF. Dabigatran and postmarketing reports of bleeding. N Eng J Med 2013. [in press].

8. Weitz J, Eikelboom JW, Samama MM. New antithrombotic drugs: Antithrombotic Therapy and Prevention of Thrombosis, 9th ed: American College of Chest Physicians Evidence-Based Clinical Practice Guidelines. Chest 2012;141 (Suppl 2):e120S-51S.

9. Schulman S, Kearon C on behalf of the SubCommittee on Control of the Anticoagulation of the Scientific and Standardization Committee of the Intrnational Society of Thrombosis and Haemostasis. Definition of major bleeding in clinical investigations of antihemostatic medicinal products in non-surgical patients. J Thromb Haemost 2005;3:692-4.

10. Connolly SJ, Ezekowitz MD, Yusuf S, et al. Dabigatran versus warfarin in patients with atrial fibrillation. N Eng J Med 2009;361:1139-51.

11. Connolly SJ, Ezekowitz MD, Yusuf S, et al. Newly identified events in the RE-LY trial. $N$ Eng $J$ Med 2010;363:1875-6.

12. Patel MR, Mahaffey KW, Garg J, et al. Rivaroxaban versus warfarin in nonvalvular atrial fibrillation. $\mathrm{N}$ Engl $\mathrm{J}$ Med 2011;365:883-91.

13. Granger CB, Alexander JH, McMurray JJ et al. Apixaban versus warfarin in patients with atrial fibrillation. N Engl J Med 2011;365:981-92.

14. Masotti L, Di Napoli M, Godoy DA, et al. The practical management of intracerebral hemorrhage associated with oral anticoagulant therapy. Int J Stroke 2011;6:228-40.

15. Dzik WS. Reversal of drug-induced anticoagulation: old solutions and new problems. Transfusion 2012;52: $45 \mathrm{~S}-55 \mathrm{~S}$

16. Ageno W, Gallus AS, Wittkowsky A, et al. Oral anticoagulant therapy: Antithrombotic Therapy and Prevention of Thrombosis, 9th ed: American College of Chest Physicians Evidence-Based Clinical Practice Guidelines. Chest 2012;141:e44S-88S.

17. Penner JA. Prothrombin complex concentrates and coagulation. Ann Intern Med 1976;85:531-2.

18. Liotta EM, Garg RK, Temes RE, et al. Warfarin-associ- ated intracerebral hemorrhage is inadequately treated at community emergency departments. Stroke 2012;43: 2503-5.

19. Rodgers GM. Prothrombin complex concentrates in emergency bleeding disorders. Am J Hematol 2012;87: 898-902.

20. Schulman S, Bijsterveld NR. Anticoagulants and their reversal. Transfus Med Rev 2007;21:37-48.

21. Pernod G, Godiér A, Gozalo C, et al. French clinical practice guidelines on the management of patients on vitamin $\mathrm{K}$ antagonists in at-risk situations (overdose, risk of bleeding, and active bleeding. Thromb Res 2010;126:e167-74.

22. Keeling D, Baglin T, Tait C, et al. Guidelines on oral anticoagulation with warfarin - fourth edition. $\mathrm{Br} \mathrm{J}$ Haematol 2011;154:311-24.

23. Rossaint R, Bouillon B, Cerny V, et al. Management of bleeding following major trauma: an updated European guideline. Crit Care. 2010;14:R52.

24. Tran HA, Chunilal SD, Harper PL, et al. An update of consensus guidelines for warfarin reversal. Med J Aust 2013;198:198-9.

25. Morgenstern LB, Hemphill JC, Anderson C, et al. Guidelines for the management of spontaneous intracerebral hemorrhage: a guideline for healthcare professionals from the American Heart Association/American Stroke Association. Stroke 2010;41:2108-29.

26. Liumbruno G, Bennardello F, Lattanzio A, et al. Recommendations for the use of antithrombin concentrates and prothrombin complex concentrates. Blood Transfus 2009;7:325-34.

27. British Committee for Standards in Hematology, Blood Transfusion Task Force. Guidelines for the use of freshfrozen plasma, cryoprecipitate and cryosupernatant. $\mathrm{Br}$ J Hematol 2004;126:11-28.

28. Wójcik C, Schymik ML, Cure EG. Activated prothrombin complex concentrate factor VIII inhibitor bypassing activity (FEIBA) for the reversal of warfarin-induced coagulopathy. Int J Emerg Med 2009;2:217-25.

29. Ingerslev J, Vanek T, Culic S. Use of recombinant factor VIIa for emergency reversal of anticoagulation. J Postgrad Med 2007;53:17-22.

30. Robinson MT, Rabinstein AA, Meschia JF, Freeman WD. Safety of recombinant activated factor VII in patients with warfarin-associated hemorrhages of the central nervous system. Stroke 2010;41:1459-63.

31. Ageno W, Garcia D, Aguilar MI, et al. Prevention and treatment of bleeding complications in patients receiving vitamin $\mathrm{K}$ antagonists, Part 2 treatment. Am J Hematol 2009;84:584-8.

32. Schulman S, Bijsterveld NR. Anticoagulants and their reversal. Transfus Med Rev 2007;21:37-48.

33. Baker P, Gleghorn A, Tripp T, et al. Reversal of asymptomatic over-anticoagulation by orally administered vitamin K. Br J Haematol 2006;133:331-6.

34. Foerch C, Arai K, Jin G, et al. Experimental model of warfarin-associated intracerebral hemorrhage. Stroke 2008;39:3397-404.

35. Foerch C, Arai K, Van Cott EM, et al. Rapid reversal of anticoagulation reduces hemorrhage volume in a mouse model of warfarin-associated intracerebral hemorrhage. J Cereb Flow Metab 2009;29:1015-21.

36. Cucchiara B, Messe S, Sansing L, et al. Hematoma 
growth in oral anticoagulant related intracerebral hemorrhage. Stroke 2008;39:2293-6.

37. Flibotte JJ, Hagan N, O'Donnell J, et al. Warfarin, hematoma expansion, and outcome of intracerebral hemorrhage. Neurology 2004;63:1059-64.

38. Hanger HC, Geddes JA, Wilkinson TJ, et al. Warfarinrelated intracerebral haemorrhage: better outcomes when reversal includes prothrombin complex concentrates. Intern Med J 2013;43:308-16.

39. Lauer A, Pfeilschifter W, Schaffer CB, et al. Intracerebral haemorrhage associated with antithrombotic treatment: translational insights from experimental studies. Lancet Neurol 2013;12:394-405.

40. Levi M, Eerenberg E, Kamphuisen PW. Bleeding risk and reversal strategies for old and new anticoagulants and antiplatelet agents. J Thromb Haemost 2011;9:1705-12.

41. Paty I, Trellu M, Destors JM, et al. Reversibility of the anti-FXa activity of idrabiotaparinux (biotinylated idraparinux) by intravenous avidin infusion. J Thromb Haemost 2010;8:722-9.

42. Goldstein JN, Marrero M, Masrur S, et al. Management of thrombolysis-associated symptomatic intracerebral hemorrhage. Arch Neurol 2010;67:965-9.

43. Elmer J, Wittels KA. Emergency reversal of pentasaccharide anticoagulants: a systematic review of the literature. Transfus Med 2012;22:108-15.

44. Batchelor JS, Grayson A. A meta-analysis to determine the effect on survival of platelet transfusions in patients with either spontaneous or traumatic antiplatelet medication-associated intracranial haemorrhage. BMJ Open 2012;2:e00588.

45. Pengo V, Crippa L, Falanga A, et al. Questions and answers on the use of dabigatran and perspectives on the use of other new oral anticoagulants in patients with atrial fibrillation. A consensus document of the Italian Federation of Thrombosis Centers (FCSA). Thromb Haemost 2011;106:868-76.

46. Palareti G, Ageno W, Ferrari A, et al. Clinical management of rivaroxaban-treated patients. Expert Opin Pharmacother 2013;14:655-67.

47. van Ryn J, Stangier J, Haertter S, et al. Dabigatran etexilate-a novel, reversible, oral direct thrombin inhibitor: interpretation of coagulation assays and reversal of anticoagulant activity. Thromb Haemost 2010;103:1116-27.

48. Kaatz S, Kouides PA, Garcia DA, et al. Guidance on the emergent reversal of oral thrombin and factor Xa inhibitors. Am J Hematol 2012;87:S141-5.

49. Pragst I, Zeitler SH, Doerr B, et al. Reversal of dabigatran anticoagulation by prothrombin complex concentrate (Beriplex $\mathrm{P} / \mathrm{N}$ ) in a rabbit model. J Thromb Haemost 2012;10: 1841-8.

50. Zhou W, Schwarting S, Illanes S, et al. Hemostatic therapy in experimental intracerebral hemorrhage associated with the direct thrombin inhibitor dabigatran. Stroke 2011;42:3594-9.

51. Fukuda T, Honda Y, Kamisato C, et al. Reversal of anticoagulant effects of edoxaban, an oral, direct factor Xa inhibitor, with haemostatic agents. Thromb Haemost 2012;107:253-9.

52. Bauer KA. Reversal of antithrombotic agents. Am J Hematol 2012;87:S119-26.

53. Marlu R, Hodaj E, Paris A, et al. Effect of non-specific reversal agents on anticoagulant activity of dabigatran and rivaroxaban: a randomised crossover ex vivo study in healthy volunteers. Thromb Haemost 2012;108:217-24.

54. Khoo TL, Weatherburn C, Kershaw G, et al. The use of FEIBA ${ }^{\circledR}$ in the correction of coagulation abnormalities induced by dabigatran. Int J Lab Hematol 2013;35:222-4.

55. Stangier J, Rathgen K, Stahle H, et al. Influence of renal impairment on the pharmacokinetics and pharmacodynamics of oral dabigatran etexilate: an open-label, parallel-group, single-centre study. Clin Pharmacokinet 2010;49:259-68.

56. Eerenberg ES, Kamphuisen PW, Sijpkens MK, et al. Reversal of rivaroxaban and dabigatran by prothrombin complex concentrate: a randomized, placebo-controlled, crossover study in healthy subjects. Circulation 2011;124:1573-9.

57. Harper P, Young L, Merriman E. Bleeding risk with dabigatran in the frail elderly. N Engl J Med 2012; 366:864-6.

58. Harinstein LM, Morgan JW, Russo N. Treatment of Dabigatran-Associated Bleeding: Case Report and Review of the Literature. J Pharm Pract 2012. [Epub ahead of print].

59. Berger R, Salhanick SD, Chase M, Ganetsky M. Hemorrhagic complications in emergency department patients who are receiving dabigatran compared with warfarin. Ann Emerg Med 2013;61:475-9.

60. Lu G, Deguzman FR, Hollenbach SJ, et al. A specific antidote for reversal of anticoagulation by direct and indirect inhibitors of coagulation factor Xa. Nat Med 2013;19:446-51.

61. Schiele F, van Ryn J, Canada K, et al. A specific antidote for dabigatran: functional and structural characterization. Blood 2013. [Epub ahead of print].

62. Siegal DM, Crowther MA. Acute management of bleeding in patients on novel oral anticoagulants. Eur Heart J 2013;34:489-500.

63. Kaatz S, Kouides PA, Garcia DA, et al. Guidance on the emergent reversal of oral thrombin and factor Xa inhibitors. Am J Hematol 2012;87:S141-5.

64. Frank Peacock W, Gearhart MM, Mills RM. Emergency management of bleeding associated with odl and new oral anticoagulants. Clin Cardiol 2012. [Epub ahead of print].

65. Alikhan R, Rayment R, Keeling D, et al. The acute management of haemorrhage, surgery and overdose in patients receiving dabigatran. Emerg Med J 2013. [Epub ahead of print].

66. Turpie AGG, Kreutz R, Llau J, et al. Management consensus guidance for the use of rivaroxaban -an oral, direct factor Xa inhibitor. Thromb Haemost 2012;108: 876-86.

67. Huisman MV, Lip GYH, Diener HC, et al. Dabigatran etexilate for stroke prevention in patients with atrial fibrillation: resolving uncertainties in routine practice. Thromb Haemost 2012;107:838-47.

68. Stangier J, Clemens A. Pharmacology, pharmacokinetics, and pharmacodynamics of dabigatran etexilate, an oral direct thrombin inhibitor. Clin Appl Thromb Hemost 2009; 15:9S-16S.

69. Weinz C, Schwarz T, Kubitza D, et al. Metabolism and excretion of rivaroxaban, an oral, direct factor Xa inhibitor, in rats, dogs, and humans. Drug Metab Dispos 2009;37:1056-64. 
70. Raghavan N, Frost CE, Yu Z, et al. Apixaban metabolism and pharmacokinetics after oral administration to humans. Drug Metab Dispos 2009;37:74-81.

71. Garcia D, Barrett YC, Ramacciotti E, Weitz JI. Laboratory assessment of the anticoagulant effects of the next generation of oral anticoagulants. J Thromb Haemost 2013;11:245-52.

72. Douxfils J, Mullier F, Robert S, et al. Impact of dabigatran on a large panel of routine or specific coagulation assays. Laboratory recommendations for monitoring of dabigatran etexilate. Thromb Haemost 2012;107:985-97.

73. Douxfils J, Mullier F, Loosen C, et al. Assessment of the impact of rivaroxaban on coagulation assays: laboratory recommendations for the monitoring of rivaroxaban and review of the literature. Thromb Res 2012;130:956-66.

74. van Ryn J, Stangier J, Haertter S, et al. Dabigatran etexilate-a novel, reversible, oral direct thrombin inhibitor: interpretation of coagulation assays and reversal of anticoagulant activity. Thromb Haemost 2010;103: 1116-27.

75. Samama MM. Which test to measure the anticoagulant effect of rivaroxaban? The anti-xa assay. J Thromb Haemost 2013. [Epub ahead of print].
76. Tripodi A. The laboratory and the new oral anticoagulants. Clin Chem 2013;59:353-62.

77. Baglin T, Keeling D, Kitchen S; British Committee for Standards in Haematology. Effects on routine coagulation screens and assessment of anticoagulant intensity in patients taking oral dabigatran or rivaroxaban: guidance from the British Committee for Standards in Haematology. Br J Haematol 2012;159:427-9.

78. Baglin T, Hillarp A, Tripodi A, et al. Measuring Oral Direct Inhibitors (ODIs) of thrombin and factor Xa: A recommendation from the Subcommittee on Control of Anticoagulation of the Scientific and Standardisation Committee of the International Society on Thrombosis and Haemostasis. J Thromb Haemost 2013. [Epub ahead of print].

79. Díaz MQ, Borobia AM, Núñez MA, et al. Use of prothrombin complex concentrates for urgent reversal of dabigatran in the emergency department. Haematologica 2013;98:e143-4.

80. Pernod G, Albaladejo P, Godier A, et al. Management of major bleeding complications and emergency surgery in patients on long-term treatment with direct oral anticoagulants, thrombin or factor-Xa inhibitors: proposals of the working group on perioperative haemostasis (GIHP) March 2013. Arch Cardiovasc Dis 2013;106: 382-93. 